Historic, archived document

Do not assume content reflects current scientific knowledge, policies, or practices. 



\section{for Monitoring Spotted Owls in Oregon and Washington in 1987}

Timothy A. Max, Ray A. Souter, and Kathleen A. O'Halloran

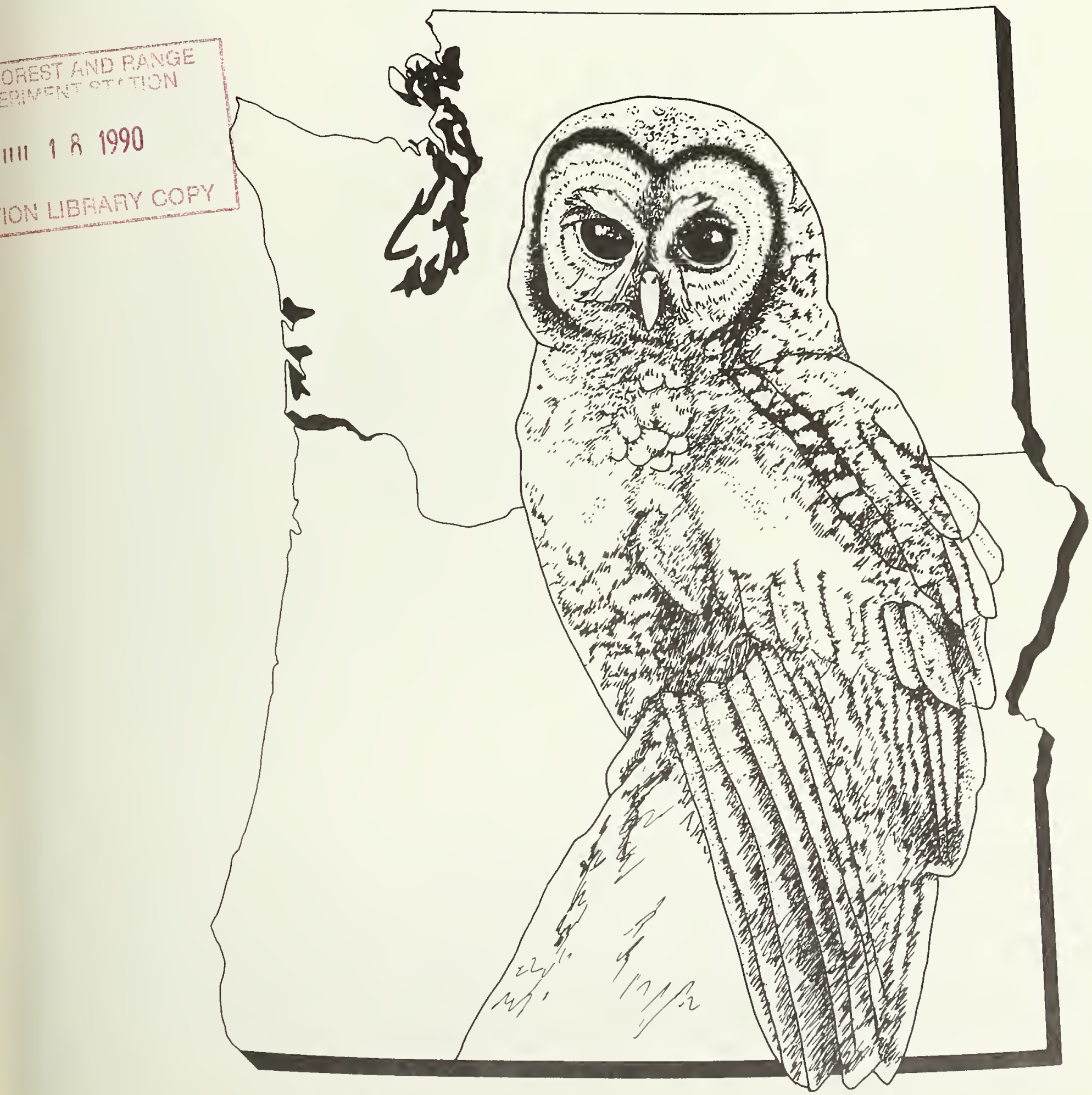


TIMOTHY A. MAX is the Station statistician, Pacific Northwest Research Station, P.O. Box 3890, Portland, Oregon 97208-3890. RAY A. SOUTER is a mathematical statistician, Southeastern Forest Experiment Station, Forestry Sciences Laboratory, Carlton St., Athens, Georgia 30602. When the work was done, he was with the Pacific Northwest Research Station. KATHLEEN A. O'HALLORAN is a wildlife biologist, Pacific Northwest Region, P.O. Box 3623, Portland, Oregon 97208-3623. When the work was done, she was with the Pacific Northwest Research Station. 


\section{Abstract}

Summary
Max, Timothy A.; Souter, Ray A.; O'Halloran, Kathleen A. 1990. Statistical estimators for monitoring spotted owls in Oregon and Washington in 1987. Res. Pap. PNW-RP-420. Portland, OR: U.S. Department of Agriculture, Forest Service, Pacific Northwest Research Station. 13 p.

Spotted owls (Strix occidentalis) were monitored on 11 National Forests in the Pacific Northwest Region of the USDA Forest Service between March and August of 1987. The basic intent of monitoring was to provide estimates of occupancy and reproduction rates for pairs of spotted owls. This paper documents the technical details of the statistical estimation procedures used to produce all the estimates resulting from that effort. All relevant formulae are presented as well as decisions made about collapsing strata to estimate variances. Some complicating aspects of the monitoring effort are also discussed.

Keywords: Spotted owl, Strix occidentalis, sampling, stratified random sampling, monitoring.

Spotted owls (Strix occidentalis) were monitored on 11 National Forests in the Pacific Northwest Region of the USDA Forest Service between March and August of 1987. The objective was to provide estimates of occupancy and reproduction rates for three distinct subpopulations consisting of different land classification types as defined in the Pacific Northwest Region. Over time, point estimates from 1987 will be used with point estimates from other years to establish trends. The sampling design consisted of stratified random sampling independently designed and implemented for each subpopulation. This paper documents the technical details of the statistical estimation procedures used to summarize the data obtained from sampling. All relevant formulae are presented as well as decisions made about collapsing strata to estimate variances. Field protocols used to obtain all measurements may have resulted in the biasing of some estimates. Two sources of potential bias were misclassification of occupancy of sites and failure to detect multiple occupancy. These sources of potential bias are thoroughly discussed. 
Contents

1 Introduction

1 Population

2 Sampling Design

3 Estimators for Stratified Sampling

3 Notation

3 Case 1, Continuous Variables

4 Case 2, Simple Categorical Variables

5 Case 3, Complicated Categorical Variables

$6 \quad$ Estimating Occupancy

10 Estimating Reproduction

11 Sources of Potential Bias

13 Literature Cited 
Introduction

Population
During summer 1987, spotted owls (Strix occidentalis) were monitored on National Forest land in the Pacific Northwest Region (Region 6) of the USDA Forest Service. The general objective of monitoring was to provide estimates, for three distinct land classifications, of occupancy by pairs and of reproductive rates of the spotted owls. The results of this monitoring as well as details about the objectives and methods were provided in a report prepared by the USDA Forest Service. ${ }^{1}$ The purpose of this paper is to document the technical details of the statistical estimation procedures used to produce the results presented in that report.

To understand the estimation procedures used, it is necessary to have a clear understanding of the three distinct land classifications used in the sampling process. These three land classifications, defined completely in the next paragraph, specify three distinct subpopulations of land area within Region 6. Each of these subpopulations was sampled independently by using area sampling methods. It is important to clearly understand that in this sampling design, the term "subpopulation" refers to a distinct type of land area defined by the land classification definitions given in the next paragraph.

Definitions of land classes were based on two factors. First, land was classified as "reserved" or "nonreserved." Reserved land is specifically designated as "withdrawn from timber harvesting activities," as specified by law or administrative decision by the Chief of the Forest Service; examples are wilderness areas and research natura! areas. Nonreserved land is generally available for timber harvesting. This class included some land currently classified as "not suitable for timber harvest." The second factor was whether or not land was designated as a spotted owl habitat area (SOHA). ${ }^{2}$ In 1987, SOHAs were established on both reserved and nonreserved land. Thus four distinct land classifications were reserved non-SOHA, reserved SOHA, nonreserved non-SOHA, and nonreserved SOHA. Reserved non-SOHA land was not specifically included in the population for this monitoring effort. The three subpopulations sampled in 1987 were, therefore, the other three land classifications; that is, reserved SOHA, nonreserved non-SOHA, and nonreserved SOHA.

Within the three defined subpopulations, land area was further classified into physiographic provinces (Franklin and Dyrness 1973) and National Forests. Eleven National Forests were included in the 1987 monitoring, because as of March 1987, SOHA networks had been well established on 11 of the 13 National Forests in Region 6 where spotted owls occur. The 11 National Forests and physiographic provinces are identified in table 1.

\footnotetext{
${ }^{1}$ USDA Forest Service, Pacific Northwest Region. FY87 annual report: spotted owl inventory and monitoring. Portland, OR. Administrative report. On file with: Pacific Northwest Region, P.O. Box 3623, Portland, OR 97208-3623.

${ }^{2}$ Guidelines used for establishing and spacing SOHAs are contained in a letter from the Regional Forester to Forest Supervisors: letter 1920, February 9, 1983. On file with: Fish and Wildlife Staff, Pacific Northwest Region, P.O. Box 3623, Portland, OR 97208-3623.
} 
Table 1-Physiographic provinces, acronyms used to reference the provinces, and National Forests monitored for spotted owls in 1987

\begin{tabular}{lll}
\hline Physiographic province & $\begin{array}{l}\text { Province } \\
\text { acronym }\end{array}$ & National Forests \\
\hline Olympic Peninsula & OLPE & Olympic \\
Washington Cascade Range & WACA & $\begin{array}{l}\text { Mount Baker-Snoqualmie } \\
\text { Gifford Pinchot }\end{array}$ \\
Oregon Cascade Range & ORCA & $\begin{array}{l}\text { Mount Hood } \\
\text { Willamette } \\
\text { Umpqua } \\
\text { Rogue River } \\
\text { Deschutes } \\
\text { Winema }\end{array}$ \\
Coast Ranges of Oregon & CORA & $\begin{array}{l}\text { Siuslaw } \\
\text { Klamath }\end{array}$ \\
& KLAM & $\begin{array}{l}\text { Siskiyou } \\
\text { Rogue River }\end{array}$ \\
\hline
\end{tabular}

${ }^{a}$ The Rogue River National Forest was divided between the ORCA and the KLAM provinces.

Most estimates were provided separately for the three defined subpopulations. Some estimates were provided by physiographic province, and others were made for groups of physiographic provinces. Other estimates were provided only for the specific subpopulation for the entire portion of Region 6 that was monitored. No estimates were provided for individual National Forests.

The sampling design used in each of the three subpopulations was stratified random sampling. Strata were the National Forests. Sample sizes were independently established for each of the three subpopulations as described in the "FY87 Annual Report" (see footnote 1). Within subpopulations, sample units were allocated among the National Forest strata approximately proportionally to stratum size.

Different sampling units were defined for the different subpopulations. For the reserved and nonreserved SOHAs, sampling units were the 1000-acre designated SOHAs. The SOHA definition used for 1987 monitoring was 1000 acres of suitable or capable spotted owl habitat delineated within a 1.5-mile-radius circle (4500 acres) centered on a location of owl activity. Forests had delineated 2200-acre SOHAs for planning purposes, but 1987 monitoring was based only on the field work conducted within the 1000-acre boundary. In the nonreserved non-SOHA land, sample units consisted of all the area in a 1.5-mile-radius circle, or 4500 acres. 


\section{Estimators for Stratified Sampling}

Notation

Case 1, Continuous Variables
Three basic types of stratified estimators were used in this survey, depending on the type of response variable measured. The three types of response variables were (1) continuous variables, (2) simple categorical variables with two possible classes, and (3) more complicated categorical variables. This more complicated categorical variable occurred when an observation was first classified as a simple categorical variable and then one of the original classes was further subdivided into two possible categories. Appropriate estimators will be presented for each of these three types of response variables.

The following notation will be used throughout. This notation and the formulae used follow Cochran (1977, chapter 5).

$h$ is a subscript denoting a stratum and ranging from 1 to $L$,

$L$ is the number of strata in a population (that is, the number of National Forests in the population),

$\mathrm{i}$ is a subscript denoting a particular sampling unit within a stratum,

$\mathrm{N}_{\mathrm{h}}$ is the number of units in stratum $\mathrm{h}$,

$N$ is the number of units in the population $=\sum_{h=1}^{L} N$,

$W_{h}=N_{h} / N$ is the stratum weight,

$\mathrm{n}_{\mathrm{h}}$ is the number of units selected in the sample from stratum $\mathrm{h}$,

$n$ is the total sample size $=\sum_{h=1}^{L} n_{h}$, and

$f_{h}=n_{h} / N_{h}$ is the sampling fraction in stratum $h$.

If the response variable was continuous, then the straightforward stratified estimator for the mean is

$$
\bar{y}_{s t}=\sum_{h=1}^{L} W_{h} \bar{y}_{h}
$$

where

$\bar{y}_{h}=\left(1 / n_{h}\right) \sum_{i=1}^{n_{h}} y_{h i}$, and

Yhi $=$ response measured on the ith sample unit in stratum $\mathrm{h}$.

The estimated variance of $\bar{y}_{s t}$ is

$$
v\left(\bar{y}_{s t}\right)=\sum_{h=1}^{L} W_{h}^{2}\left(1-f_{h}\right) s h^{2} / n_{h},
$$


where

$S h^{2}=\frac{1}{n_{h}-1} \sum_{i=1}^{n h}(y h-\bar{y} h)^{2}$ is the sample variance for stratum $h$.

The standard error of $\bar{y}_{s t}$ is

$$
\text { s.e. }\left(\bar{y}_{s t}\right)=\left[v\left(\bar{y}_{s t}\right]^{1 / \bar{c}} .\right.
$$

Approximate $100(1-\alpha)$ percent confidence intervals for $\bar{y}_{\text {st }}$ are constructed as

$$
\bar{y}_{s t} \pm(t)\left[s . e .\left(\bar{y}_{s t}\right)\right]
$$

where

$\mathrm{t}=$ the $\alpha / 2$ percentage point of the $\mathrm{t}$-distribution with $\mathrm{n}_{\mathrm{e}}$ degrees of freedom.

$$
n_{e}=\left[\sum_{h=1}^{L} g h S h^{2}\right]^{2} /\left[\sum_{h=1}^{L} g h^{2} S h^{4} /(n h-1)\right]
$$

where

$g_{h}=N_{h}\left(N_{h}-n_{h}\right) / n_{h}$,

and is an approximate method of assigning an effective number of degrees of freedom to s.e. $\left(\bar{y}_{\mathrm{st}}\right)$ (Cochran 1977, equation 5.16). The construction of confidence intervals by this method assumes $\bar{y}_{\text {st }}$ is normally distributed. The computation of $n_{e}$ assumes the variable, yhi, is normally distributed.

Case 2, Simple Categorical Variables
If the response variable is categorical, with two possible responses, then the objective is to estimate the proportion in one of the classes. To develop an estimator for this situation, define ah as the number of sample units in stratum $\mathrm{h}$ with the desired characteristic (that is, the number of sample units in the class of interest).

$$
\hat{p}_{s t}=\sum_{h=1}^{L} W_{h} \hat{p}_{h}
$$

where

$\widehat{\mathrm{P}}_{h}=a_{h} / n_{h}$. 
An unbiased estimator of variance of $\hat{p}_{\text {st }}$ is

$$
v\left(\hat{p}_{s t}\right)=\sum_{h=1}^{L} W_{h}^{2}[v(\widehat{p h})],
$$

where

$v\left(\hat{p}_{h}\right)=\left(1-f_{h}\right)\left(\hat{p}_{h}\right)\left(1-\hat{p}_{h}\right) /\left(n_{h}-1\right)$

The standard error of $\hat{p}_{\text {st }}$ is then

$$
\text { s.e. }\left(\hat{p}_{s t}\right)=\left[v\left(\hat{p}_{s t}\right)\right]^{1 / 2} \text {. }
$$

Approximate $100(1-\alpha)$ percent confidence intervals can be computed for $\hat{p}_{\text {st }}$ as

$$
\hat{p}_{s t} \pm t\left[s . e \cdot\left(\hat{p}_{s t}\right)\right]
$$

where

$t$ is the $\alpha / 2$ percentage point of the $t$-distribution with $n_{e}$ degrees of freedom, and

$\mathrm{n}_{e}$ is computed as in equation (4) with

$$
s h^{2}=\frac{n_{h}}{n_{h}-1}\left(\hat{p}_{h}\right)\left(1-\hat{p}_{h}\right) \text { and }
$$

$\mathrm{gh}$ is as defined before.

Although these approximate confidence intervals can be computed, the necessary assumptions are not met. The necessary assumptions are that $p_{s t}$ is approximately normally distributed and, to compute $\mathrm{n}_{\mathrm{e}}$, that the variable, $\mathrm{yhi}$, is normally distributed. Clearly $y$ hi is a categorical variable with values of either 0 or 1 and does not meet the assumption of normality. So the nominal probability level of these confidence intervals will be smaller than the actual probability level. The amount of the difference between the nominal and actual probability levels is not known.

Case 3, Complicated Categorical Variables
For complicated categorical variables, sample units were initially classified into one of two classes as for case 2. We let $A_{0}$ and $A_{1}$ represent the two classes. After the sample was classified by this criteria, units classified as $A_{1}$ were examined further and classified by another criteria into one of two categories, say $B_{0}$ or $B_{1}$. The objective was to estimate the proportion classified as $B_{1}$ within those classified as $A_{1}$. An example of using this more complicated categorical variable was in estimating reproduction. We let the $A$ criteria represent occupancy by a pair; that is, units classified $A_{0}$ were not occupied and units classified $A_{1}$ were occupied. We let the $B$ criteria represent occurrence of reproduction; that is, units classified Bo had no young owls observed whereas units classified $B_{1}$ had young owls observed. One objective was to estimate the proportion of occupied sites where reproduction occurred. 
First, we will define some notation to help understand this situation. Let an be the number of units classified $A_{1}$, and $b_{h}$ be the number of units in $A_{1}$ that are classified $B_{1}$.

Within a particular stratum, the estimated proportion of $A_{1}$ 's classified as $B_{1}$ is $b_{h} / a_{h}$. And a consistent estimate of the variance of bh/ah (from Sukhatme and Sukhatme 1970: $27-30)$ is

$$
v(b h / a h)=\left(1-f_{h}\right)\left(b_{h} / a_{h}{ }^{2}\right)(1-b h / a h)
$$

Putting these estimators into the stratified estimators results in an overall estimate, for the population, of the proportion classified as $A_{1}$ that are also $B_{1}$. We will call this estimated proportion $\left(p_{11}\right)_{\text {st. }}$. So the estimator is

$$
\left(\hat{p}_{11}\right)_{s t}=\sum_{h=1}^{L} W_{h}\left(b_{h} / a_{h}\right) .
$$

A consistent estimator for the variance of $\left(\hat{p}_{11}\right)_{\text {st }}$ is

$$
v\left(\hat{p}_{11}\right) s t=\sum_{h=1}^{L} W_{h}{ }^{2} v\left(b_{h} / a_{h}\right)
$$

Estimating Occupancy where $v\left(b_{h} / a_{h}\right)$ is defined in equation (8).

The proportion of all sites occupied by a pair of owls was estimated separately for each subpopulation. Region-wide estimates were provided for each subpopulation. Estimates for each of the five physiographic provinces (table 1) were also provided for the nonreserved SOHA subpopulation.

The stratified estimator (equation 5) for a population proportion was used to provide each estimate. The individual National Forests (table 1) were the strata used in estimating proportions (equation 5) and their standard errors (equation 6). Owing to small sample sizes in some National Forests, some forests were combined for computing standard errors. In all cases, National Forests that were combined were near each other geographically, so pooling was also supported by the geographic similarity of the units chosen to be pooled. Tables 2, 3, and 4 document the strata used to provide the estimates of the proportion of all sites occupied by a pair of owls and their associated standard errors. The size (number of potential sampling units) of each strata and the sample size in each strata are also provided. 
Table 2-Sizes of strata a and samples In the nonreserved SOHA subpopulation used to estimate the proportion of sites occupied, by physiographic province

\begin{tabular}{llcc}
\hline $\begin{array}{l}\text { Physiographic } \\
\text { province }\end{array}$ & \multicolumn{1}{c}{$\begin{array}{c}\text { National } \\
\text { Forest }\end{array}$} & $\begin{array}{c}\text { Number of } \\
\text { nonreserved } \\
\text { SOHAs }^{b}\end{array}$ & $\begin{array}{c}\text { Number of SOHAs } \\
\text { sampled }^{c}\end{array}$ \\
\hline OLPE & Olympic & 25 & 25 \\
WACA & Gifford Pinchot & 35 & 14 \\
& Mount Baker-Snoqualmie & 44 & 31 \\
ORCA & Deschutes & 8 & 2 \\
& Mount Hood & 45 & 13 \\
& Rogue River & 16 & 3 \\
& Umpqua & 38 & 13 \\
& Willamette & 62 & 22 \\
CORA & Winema & 7 & 2 \\
KLAM & Siuslaw & 25 & 24 \\
& Rogue River & 8 & 5 \\
& Siskiyou & 22 & 9 \\
\hline
\end{tabular}

a Strata are National Forests.

${ }^{b}$ Number is stratum size.

${ }^{c}$ Number is sample size.

Table 3-Sizes of strata ${ }^{a}$ and samples in the reserved SOHA subpopulation used to estimate the proportion of sites occupled, by National Forest

\begin{tabular}{lrcc}
\hline $\begin{array}{l}\text { National } \\
\text { Forest }\end{array}$ & $\begin{array}{c}\text { Number of } \\
\text { reserved SOHAs }^{b}\end{array}$ & $\begin{array}{c}\text { Number of } \\
\text { reserved SOHAs } \\
\text { sampled }^{c}\end{array}$ & $\begin{array}{c}\text { Forest strata } \\
\text { combined for } \\
\text { variance estimation }\end{array}$ \\
\hline Olympic & 4 & 3 & \\
Mount Baker-Snoqualmie & 41 & 18 & \\
Gifford Pinchot & 7 & 6 & \\
Mount Hood & 6 & 3 & $x$ \\
Willamette & 16 & 6 & $x$ \\
Siuslaw & 15 & 1 & \\
Rogue River & 4 & 1 & \\
Siskiyou & 18 & 6 & \\
Umpqua & 3 & 3 & \\
Rogue River & 5 & 2 & \\
Deschutes & 2 & 0 & \\
Winema & 2 & 0 & \\
\hline
\end{tabular}

${ }^{a}$ Strata are National Forests.

${ }^{b}$ Number is stratum size.

c Number is sample size.

${ }^{d}$ National Forest strata followed by the same letter were combined for estimating the variance.

- The Rogue River National Forest was divided into two strata. 
Table 4-Sizes of strata ${ }^{a}$ and samples in the nonreserved non-SOHA subpopulation used to estimate the proportion of sites occupied, by National Forest

\begin{tabular}{lccc}
\hline $\begin{array}{l}\text { National } \\
\text { Forest }\end{array}$ & $\begin{array}{c}\text { Number of } \\
\text { sampling units } \\
\text { on Forest }\end{array}$ & $\begin{array}{c}\text { Number of } \\
\text { sampling units } \\
\text { sampled }\end{array}$ & $\begin{array}{c}\text { Forest strata } \\
\text { combined for } \\
\text { variance estimation }\end{array}$ \\
\hline Olympic & 117 & 5 & \\
Mount Baker-Snoqualmie & 228 & 9 & \\
Gifford Pinchot & 259 & 9 & \\
Mount Hood & 157 & 5 & \\
Willamette & 263 & 10 & \\
Siuslaw & 122 & 5 & \\
Rogue River & 109 & 5 & \\
Siskiyou & 179 & 7 & \\
Umpqua & 184 & 8 & \\
Deschutes & 164 & 4 & \\
Winema & 26 & 1 & \\
\hline
\end{tabular}

${ }^{a}$ Strata are National Forests.

${ }^{b}$ Number is stratum size.

${ }^{c}$ Number is sample size.

${ }^{d}$ National Forest strata followed by the same letter were combined for estimating the variance.

Table 4 illustrates the combining of strata to provide an estimate of standard error. All 11 forests were considered as strata for estimating the proportion of occupied sites in the nonreserved non-SOHA subpopulation. The Winema National Forest strata had a sample size of one, so it was not possible to compute a standard error for that strata. The Deschutes and Winema National Forests therefore were combined and a standard error was computed for this combined strata to produce a combined strata with a sample size of five $(4+1)$ and a strata size of $190(164+26)$. This one combined strata was used in place of the two individual strata for computing s.e.( $\left.\hat{\mathrm{p}}_{\mathrm{st}}\right)$ (equation 6$)$.

Occupancy by a pair of owls with young can be computed by using two different proportions that provide different pieces of information. One way is to compute the proportion of sites occupied by a reproductive pair that is based on all sites in the population (equation 5). A second method of computing the proportion of sites occupied by a reproductive pair is to base the proportion only on sites occupied by pairs. In this case, a random variable, the number of sites occupied by a pair, is the denominator of the computed proportion. An alternative estimator (equation 9), designed to estimate a proportion of a proportion, must be used in this case. The associated estimator of standard error is given in equation (10). Both methods were used so that the two different pieces of information provided by the two methods are available.

In 1987, no data on occurrence of young were collected for the nonreserved nonSOHA subpopulation, so estimates of occupancy by pairs with young could not be provided for this subpopulation. For the reserved and nonreserved SOHA subpopulations, all estimates were provided only for these two land classifications combined but with the five original physiographic provinces collapsed into three groups of provinces. The three groups of provinces were (1) OLPE and WACA, (2) ORCA, and 
Table 5-Sizes of strata ${ }^{a}$ and samples in the combined reserved and nonreserved SOHA population used to estimate the proportion of sites occupied by reproductive pairs, the proportion of occupied sites that contained reproductive pairs, and the average number of young produced over all sites, by physiographic province group

\begin{tabular}{|c|c|c|c|c|c|}
\hline $\begin{array}{l}\text { Physio- } \\
\text { graphic } \\
\text { province } \\
\text { group }\end{array}$ & $\begin{array}{l}\text { Land } \\
\text { classi- } \\
\text { fication }\end{array}$ & $\begin{array}{c}\text { National } \\
\text { Forest }\end{array}$ & $\begin{array}{l}\text { Number of } \\
\text { areas in } \\
\text { Forest }^{b}\end{array}$ & $\begin{array}{l}\text { Number of } \\
\text { areas } \\
\text { sampled }^{c}\end{array}$ & $\begin{array}{c}\text { Forest strata } \\
\text { combined for } \\
\text { variance } \\
\text { estimation }^{d}\end{array}$ \\
\hline \multirow{6}{*}{$\begin{array}{l}\text { OLPE } \\
\text { and } \\
\text { WACA }\end{array}$} & \multirow[t]{3}{*}{ Nonreserved } & Gifford Pinchot & 35 & 14 & \\
\hline & & Mount Baker-Snoqualmie & 44 & 31 & \\
\hline & & Olympic & 25 & 25 & \\
\hline & \multirow[t]{3}{*}{ Reserved } & Gifford Pinchot & 7 & 6 & \\
\hline & & Mount Baker-Snoqualmie & 41 & 18 & \\
\hline & & Olympic & 4 & 3 & \\
\hline \multirow[t]{10}{*}{ ORCA } & \multirow[t]{6}{*}{ Nonreserved } & Deschutes & 8 & 2 & \\
\hline & & Mount Hood & 45 & 13 & \\
\hline & & Rogue River & 16 & 3 & \\
\hline & & Umpqua & 38 & 13 & \\
\hline & & Willamette & 62 & 22 & \\
\hline & & Winema & 7 & 2 & \\
\hline & \multirow[t]{4}{*}{ Reserved } & Mount Hood & 6 & 3 & \\
\hline & & Rogue River & 5 & 2 & \\
\hline & & Umpqua & 3 & 3 & \\
\hline & & Willamette & 16 & 6 & \\
\hline \multirow{6}{*}{$\begin{array}{l}\text { CORA } \\
\text { and } \\
\text { KLAM }\end{array}$} & \multirow[t]{3}{*}{ Nonreserved } & Rogue River & 8 & 5 & \\
\hline & & Siskiyou & 22 & 9 & \\
\hline & & Siuslaw & 25 & 24 & \\
\hline & \multirow[t]{3}{*}{ Reserved } & Rogue River & 4 & 1 & $x$ \\
\hline & & Siskiyou & 18 & 6 & $x$ \\
\hline & & Siuslawe & 15 & 1 & $x$ \\
\hline
\end{tabular}

a Strata are National Forests.

bumber is stratum size.

c Number is sample size.

National Forest strata followed by the same letter were combined for estimating the variance.

- The Siuslaw reserved strata was omitted from the population when the proportion of occupied sites containing a reproductive pair was estimated. The one sample unit in this strata was not occupied.

(3) KLAM and CORA. Estimates were provided for these three groups of provinces, as well as for the entire Region, for the combined reserved and nonreserved subpopulations. Estimates for each of these situations were computed by using both methods of estimating occupancy by pairs with young as described above. The original strata were maintained for estimation; for example, typical strata are two from the Umpqua National Forest. The reserved SOHA lands and the nonreserved SOHA lands on the Umpqua National Forest are each separate strata.

Table 5 indicates that the reserved and nonreserved SOHA subpopulations were combined to produce estimates of the proportion of all sites occupied by reproductive 


\section{Estimating Reproduction}

pairs for the physiographic province groups and for the Region. To produce estimates of the standard error, however, it was necessary to combine the reserved SOHAs of the Rogue River, Siskiyou, and Siuslaw National Forests in the CORA and KLAM physiographic province group. This was done because the Rogue River and Siuslaw National Forests each had only a single sample observed in the reserved land status.

Estimates of the proportion of occupied sites that were occupied by a reproductive pair used the same strata as described above with one exception. The single exception is the reserved SOHA lands in the Siuslaw National Forest that were omitted from the population. This occurred because the single sample observed was not occupied by a pair; thus, no information pertinent to this proportion for this National Forest was available. These strata are summarized in table 5.

Estimates of the average number of young per site were provided for the three physiographic province groups (defined above) and the Region. The stratified estimators for the population mean (equation 1) and its standard error (equation 2) were used to obtain estimates for the combined reserved and nonreserved SOHA subpopulations. The strata were the same as previously described for estimating the proportion of sites occupied by a pair.

In accordance with sampling protocol, sites were classified as having owl reproduction based on observations of young. Because of the probability of predispersal mortality of young, we assumed that total number of young could be accurately counted only before July 1 . We assumed that after July 1 it was possible to accurately determine whether or not reproduction occurred at a site, but that late in the season, the observed number of young may not equal number of young produced. Therefore, for the seven sites where reproduction did occur but young were first observed after July 1 , total number of young produced could not be accurately determined. For these sites, an overall average number of young, computed from all other sites where reproduction occurred, was used in calculations. This average was based on the 17 nest sites where reproduction was documented and number of young produced was accurately determined before July 1 . If the seven censored samples had been treated as unsampled units, an unacceptable bias would have been produced in the estimated number of young per site because only sites with observed reproduction could be excluded from the sample. On the other hand, substituting an overall simple mean for these missing values may have produced a bias in the estimate of standard error. It is not clear, however, what the magnitude or direction of this bias was, because final estimates were in the context of stratified sampling. Further research is needed to decide the best approach for dealing with such missing values. One viable alternative is to use some method of statistical imputation (Sande 1982) to replace missing values with data. Sande (1982) provides a general discussion of methods of statistical imputation and problems with their implementation in practice.

Estimates of the average number of young per site occupied by a pair were provided for the three physiographic province groups and the Region. The usual stratified estimators for the population mean (equation 1) and its standard error (equation 2) are appropriate if the sample from each strata is assumed to consist only of the occupied sites. However, the sampling fraction in stratum $\mathrm{h}, \mathrm{fh}$, is calculated based 
Sources of Potential Bias

on the complete sample size and population size for the appropriate stratum, because the population size for the occupied sites is unknown. The strata used for these estimates are the same as those described for the estimates of the proportion of occupied sites that were occupied by a reproductive pair.

The field protocols used for making observations and measurements created sources of potential bias in some estimates. The protocols are briefly described in the "FY87 Annual Report" (see footnote 1) with additional details in the "Draft Monitoring and Inventorying Handbook." ${ }^{3}$ The main problem with the field protocol was that two types of measurement errors could have occurred and introduced bias into some estimates. These sources of potential bias are discussed below.

One measurement error that could have occurred was misclassifying the occupancy of a site. A site occupied by a pair of owls may have been incorrectly classified as not occupied. Given the protocol procedures, the reasons for this misclassification are that the number of visits may have been inadequate or that some pairs may remain undetected regardless of the number of visits. In 1987, sites were visited a maximum of seven times. It may also have been possible to misclassify a site as occupied when, in fact, it was not occupied. This could occur if a male and female were observed on a site but were not actually paired. Specific precautions were taken in the protocol, however, to avoid this mistake. We therefore believe that the problem caused by the first kind of misclassification error is the greater source of potential bias, and it will be discussed in more detail.

Classical sampling methods for estimating a proportion involve classifying each unit in the sample into one of two categories. The classification is assumed to be done without error, and few references discuss problems in estimation where errors in classification occur. Any such misclassification would result in biasing the proportion of sites that were occupied.

The magnitude of bias caused by pairs undetected regardless of the number of visits is not known. There is a chance that if pairs were undetected, they might be quite different in traits from those detected with the established protocol. Perhaps undetected owls are less likely to respond to calling or to offers of mice for food, or are different in any one of several other ways. This sampling methodology assumed that this is not the case. If this is the case, then the bias caused by misclassification would be greater than we suspect. This potential for bias warrants further investigation.

Bias caused by misclassification because units are visited a maximum of only seven times may be reduced by two methods. One method is to increase the maximum number of revisits before a unit is classified as not occupied. This should reduce, at least theoretically, the number of misclassifications and hence any associated bias. Each revisit is quite expensive, however. The empirical frequency distributions of

\footnotetext{
${ }^{3}$ USDA Forest Service, Pacific Northwest Region. Draft monitoring and inventorying handbook. Rev. April 6, 1987. On file with: Fish and Wildlife Staff, Pacific Northwest Region, P.O. Box 3623, Portland, OR 97208-3623.
} 

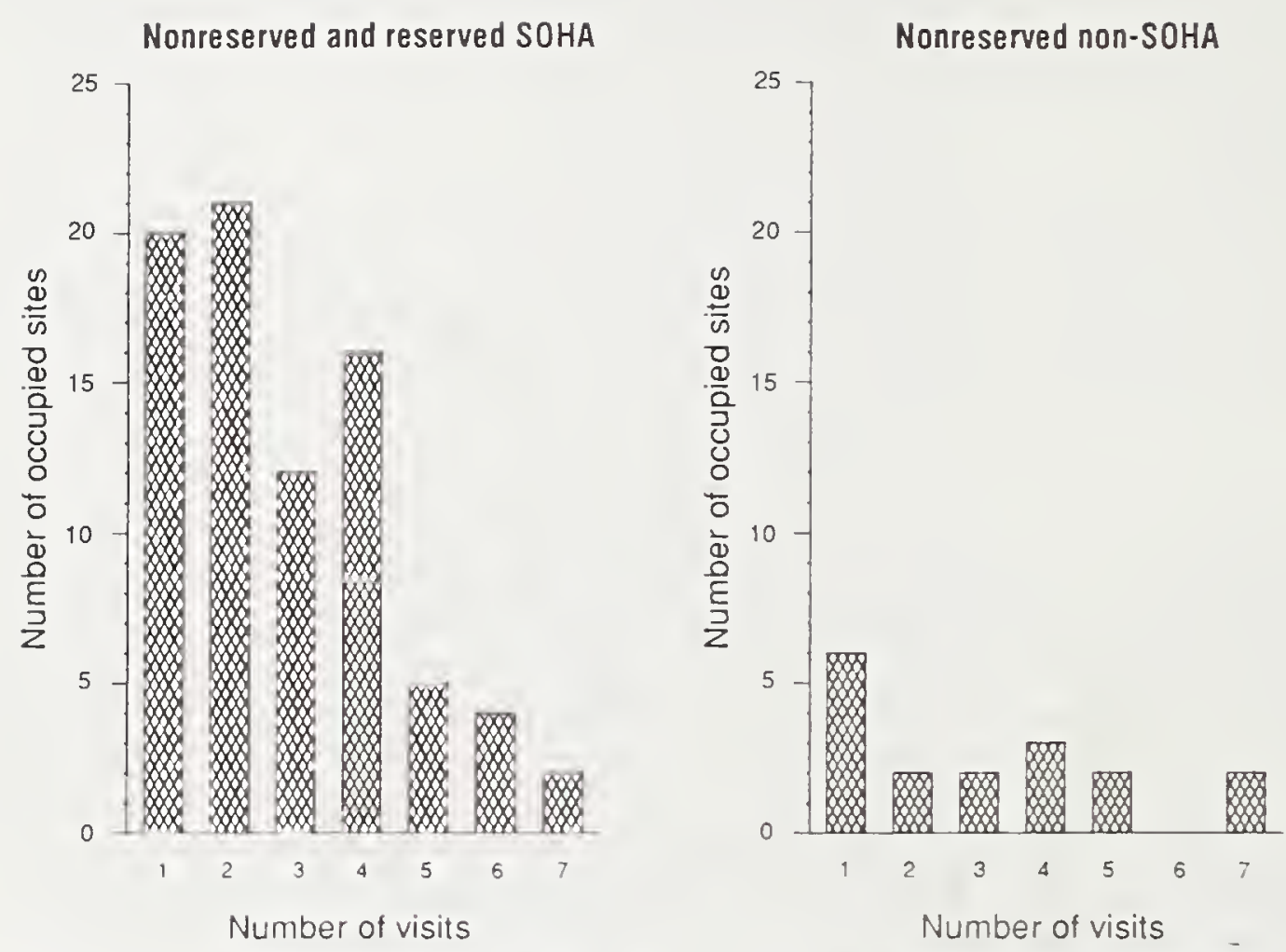

Figure 1-The observed frequency distributions of the number of visits required to establish occupancy. Distributions for the combined data from nonreserved and reserved SOHAs, as well as for the nonreserved non-SOHAs, are provided.

number of revisits required to establish occupancy (fig. 1) indicates that only a small percentage of occupied sites were classified on the seventh visit. We feel this indicates additional revisits would probably not be a cost effective way to reduce misclassifications.

A second approach to the misclassification problem associated with the number of visits is to statistically adjust the estimated proportion in an attempt to reduce the bias caused by misclassifications. An adjustment can be derived based on a probabilistic model of detecting the presence of an owl on a particular visit. Such an adjustment scheme was developed by Jim Baldwin. ${ }^{4}$ The assumptions necessary for Baldwin's statistical adjustment seemed very restrictive, however. The key assumptions were that (1) sites are completely independent, (2) successive visits to the same site are independent events, and (3) the probability of detecting a pair of owls on any particular visit is a fixed constant. In particular, the probability of detection does not change over time or between visits. Serious questions were raised about the adequacy of the data in meeting the assumptions necessary for this adjustment procedure. Because of the problems of meeting the assumptions, the decision was made that no adjustment should be made at this time. If an improved adjustment procedure were developed or the assumptions necessary for Baldwin's adjustment could be verified with data, such an adjustment might be used in future surveys.

\footnotetext{
${ }^{4}$ Personal communication with Jim Baldwin, Pacific Southwest Forest and Range Experiment Station, 1960 Addison St., Berkeley, CA 94704.
} 
A second type of error that could have affected some estimates involves occupancy by reproductive pairs. In this case, the deficiency in protocol is the lack of capability for detecting multiple occupancy of a site. The protocol followed at a site was designed to locate only the first pair of owls on the site. If a pair was identified on a site, no additional effort was made to determine if that site was occupied by another pair of owls. Multiple occupancy generally was assumed to be nonexistant or extremely unlikely.

If any multiple occupancy exists in the population, then some of the estimates of reproduction provided by the methods of this study may be biased. To see this possibility, think of a site occupied by two pairs of owls where one pair had reproduced and the other did not. If the pair that was not reproductive was identified for establishing occupancy, then the site would be classified as "not having reproduction." In this scenario, however, the site did have owl reproduction produced by the undetected pair. Under such circumstances, the source of potential bias is that sites where reproduction occurred may have been missed but nonreproductive sites would have been correctly classified.

The source of bias, described in the previous paragraph, could have potentially affected several estimates related to reproduction. These estimates are the proportion of sites occupied by a reproductive pair based on all sites in the population, the proportion of sites occupied by a reproductive pair based only on occupied sites, average number of young per site, and average number of young per site occupied by a pair. The effect of such bias on these estimates would be to produce an underestimate of the true value.

Cochran, William G. 1977. Sampling techniques. 3d ed. New York: John Wiley and Sons. $428 \mathrm{p}$.

Franklin, Jerry F.; Dyrness, C.T. 1973. Natural vegetation of Oregon and Washington. Gen. Tech. Rep. PNW-8. Portland, OR: U.S. Department of Agriculture, Forest Service, Pacific Northwest Forest and Range Experiment Station. $417 \mathrm{p}$.

Sande, I.G. 1982. Imputation in surveys: coping with reality. American Statistician. 36(3): 145-152.

Sukhatme, P.V.; Sukhatme, B.V. 1970. Sampling theory of surveys with applications. Ames, IA: lowa State University Press. 452 p. 

Max, Timothy A.; Souter, Ray A.; O'Halloran, Kathleen A. 1990. Statistical estimators for monitoring spotted owls in Oregon and Washington in 1987. Res. Pap. PNW-RP-420. Portland, OR: U.S. Department of Agriculture, Forest Service, Pacific Northwest Research Station. $13 p$.

Spotted owls (Strix occidentalis) were monitored on 11 National Forests in the Pacific Northwest Region of the USDA Forest Service between March and August of 1987. The basic intent of monitoring was to provide estimates of occupancy and reproduction rates for pairs of spotted owls. This paper documents the technical details of the statistical estimation procedures used to produce all the estimates resulting from that effort. All relevant formulae are presented as well as decisions made about collapsing strata to estimate variances. Some complicating aspects of the monitoring effort are also discussed.

Keywords: Spotted owl, Strix occidentalis, sampling, stratified random sampling, monitoring.

The Forest Service of the U.S. Department of Agriculture is dedicated to the principle of multiple use management of the Nation's forest resources for sustained yields of wood, water, forage, wildlife, and recreation. Through forestry research, cooperation with the States and private forest owners, and management of the National Forests and National Grasslands, it strives-as directed by Congress-to provide increasingly greater service to a growing Nation.

The U.S. Department of Agriculture is an Equal Opportunity Employer. Applicants for all Department programs will be given equal consideration without regard to age, race, color, sex, religion, or national origin.

Pacific Northwest Research Station

319 S.W. Pine St.

P.O. Box 3890

Portland, Oregon 97208-3890 


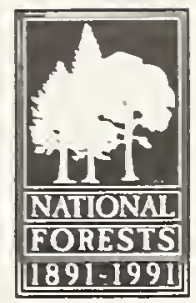

U.S. Department of Agriculture

BULK RATE POSTAGE Pacific Northwest Research Station 319 S.W. Pine Street

P.O. Box 3890

Portland, Oregon 97208

Official Business

Penalty for Private Use, $\$ 300$ 